\title{
Investigation of Contributing Factors to Scombroid Fish Poisoning among Dar es Salaam City Residents in Tanzania
}

\author{
Ngwengwe Bulula1 ${ }^{1}$, Veronica Mugoyela ${ }^{2 *}$, Eliangiringa Kaale ${ }^{2,3}$ \\ ${ }^{1}$ Tanzania Expanded Progamme on Immunization, Dar es Salaam, Tanzania \\ ${ }^{2}$ Department of Medicinal Chemistry, Muhimbili University of Health and Allied Sciences (MUHAS), Dar es Salaam, Tanzania \\ ${ }^{3}$ Pharm R\&D Lab, School of Pharmacy, Muhimbili University of Health and Allied Sciences (MUHAS), Dar es Salaam, Tanzania \\ Email: *vmugoyela@gmail.com
}

How to cite this paper: Bulula, N., Mugoyela, V. and Kaale, E. (2017) Investigation of Contributing Factors to Scombroid Fish Poisoning among Dar es Salaam City Residents in Tanzania. Open Access Library Journal, 4: e3992.

https://doi.org/10.4236/oalib.1103992

Received: September 30, 2017

Accepted: November 5, 2017

Published: November 8, 2017

Copyright $\odot 2017$ by authors and Open Access Library Inc.

This work is licensed under the Creative Commons Attribution International License (CC BY 4.0).

http://creativecommons.org/licenses/by/4.0/

\begin{abstract}
Scombroid fish poisoning is a mild to moderate form of food poisoning caused by eating spoiled or bacterial contaminated fish after capture or during subsequent handling and storage. Its symptoms are similar to those of fish allergy though it gives negative results to allergy tests. Because of that, most clinicians misdiagnose scombroid or histamine fish poisoning, and erroneously advise their patients never to eat the same fish again. A prospective descriptive cross-sectional study was carried out to assess the contributing factors of scombroid fish poisoning among fish consumers and health care personnel residents in Dar es Salaam. Results showed $49.6 \%$ of fish consumers and $60 \%$ of health care workers were aware of scombroid fish poisoning. Among those with awareness, $2.2 \%$ of fish consumers had average knowledge and the remainder had low knowledge, while $6.3 \%$ of health care workers had good knowledge, and $42.9 \%$ and $50.8 \%$ had average to low knowledge, respectively. Mackerel was frequently listed among the scombroid fish associated with scombroid fish poisoning followed by tuna and king fish. Rashes (59\%), diarrhoea (21.6\%) and skin itching (19.4\%) were the frequently mentioned symptoms by respondents. Aggressive health promotion interventions should be designed and implemented to increase awareness of histamine fish poisoning to general public including the health care personnel.
\end{abstract}

\section{Subject Areas}

Food Science \& Technology, Pharmacology

\section{Keywords}

Scombroid Fish Poisoning, Awareness, Knowledge, Respondents 


\section{Introduction}

Scombroid fish poisoning is a mild to moderate form of food poisoning caused by eating spoiled or bacterial contaminated fish after capture or during subsequent handling and storage [1] [2]. This may also occur after consuming fresh, frozen or tinned fish products which contain high amounts of histamine $(\geq 0.005 \% \mathrm{w} / \mathrm{w})$ [3] [4] [5]. Tuna and mackerel, members of the family Scombroidae, and sardines have high level of histidine and are therefore more likely to be implicated in allergic reactions [6] [7]. Histamine which is the source of fish poisoning is not present in the fresh scombroid fishes, however, it is formed as temperatures rise during storage. There is no production of histamine in fishes at $0^{\circ} \mathrm{C}[8]$.

Prevention from scombroid fish poisoning or histamine fish poisoning (HFP) needs much attention because histamine is neither destroyed by heat or cold. Hence cooking and smoking will not destroy the toxin similarly freezing and canning [1] [2]. As reported by Bulula et al. in his Master of Pharmacy dissertation [9], histamine poisoning is prevented by increasing care in handling fishes together with adequate refrigeration at or below $4^{\circ} \mathrm{C}\left(40^{\circ} \mathrm{F}\right)$ at all times. Nonetheless in the community, fish poisoning can be reduced by rejection of fresh fish kept at $>4^{\circ} \mathrm{C}$ at delivery and has already developed bad odour [9]. Fresh fish should be used within 48 hours at refrigerated temperatures [1].

The symptoms of scombroid fish poisoning can be very similar to severe allergic reactions and can occur rapidly within ten minutes to four hours of ingestion of an intoxicated fish. These may include: headache, giddiness/dizziness, nausea and vomiting, stomach aches/abdominal cramps, diarrhoea, blushes in the face, swallowing difficulties, low blood pressure, skin itching, body swellings, a burning/tingling sensation in/or around the mouth, rash and/or swelling over the chest/and or neck and diarrhoea [4] [7] [8] [10] [11] [12]. Rapid onset is one of the reasons that scombroid poisoning may be reported more often than many other food poisonings which react much slower [1]. Most of the fish poisoning symptoms usually last for approximately four to six hours and rarely exceed one to two days [1] [13].

Incidents and/or outbreaks of histamine poisonings have been reported in various places whenever raw spoiled fish were eaten. In Switzerland for 25 years (1966-1991), a total of 76 incidents after intake of tuna fish were reported to Swiss Toxicological Information Centre [14]. From 1976 to 1986, 258 incidents of suspected scombroid fish poisoning were reported in Britain. Histamine analysis was carried out on 240 fish samples from these incidents, and 101 were found to contain greater than $50 \mathrm{ppm}$ histamine [15]. In North Carolina (USA) from 1994 to 1997 an average of 2 cases annually were reported and from July 1998 to February 1999, a total of 22 cases of histamine fish poisoning were reported [16]. Between 1992 and 1999, 10\% of the infectious intestinal disease outbreaks reported to the Communicable Disease Surveillance Centre (USA) were associated with fish and about half of them to HFP [17]. Outbreaks of HFP to 378 patients suffering from Tuberculosis (TB) whom were on isoniazid (INH) 
have been reported after ingesting fish. Of these patients, 8 presented with the allergy-like symptoms including flushing, headache, palpitation, itching, wheezing, dyspnoea and diarrhoea within 20 minutes to two hours [18].

There are various tests for allergies (such as skin prick test and specific IgE blood test, RAST-type) and are specific to allergens. However, a person with histamine poisoning will always have negative allergy tests, despite having symptoms that mimic the allergic reactions [19].

In Tanzania, very little is known about histamine fish poisoning and other biogenic amines content in fish [9]. Most clinicians are unfamiliar with histamine fish poisoning. Hence they often misreport this as fish allergy, and advise their patients to avoid the source of allergens, be it fish or other foods, once they develop allergic reactions. Records from Muhimbili National Hospital showed that from March 2008 to March 2011, about 8 per 1000 patients were admitted with Steven Johnson's Syndrome following fish consumption and laboratory investigation showed that two of them were negative to allergy test (skin prick test). On the same period, about 26 per 1000 patients who attended dermatological clinic at MNH (New Outpatient Department) had complaints of skin itching, rashes and pruritus following fish consumption [20]. The current study focused on investigation of contributing factors to scombroid fish poisoning among residents of Dar es Salaam city, the capital and commercial centre of Tanzania.

\section{Methodology}

\subsection{Study Design and Sample Size}

A cross sectional study was carried out between January and March 2012 to investigate the factors associated with scombroid fish poisoning among Dar es Salaam city residents including both fish consumers and health care providers (health care personnel). Dar es Salaam region which has a population of 2,698,652 by January 2009 according to the Genomes geographical data base, and as per official 2002 census it had a population of 2,497,940 [21].

Convenient sampling was used to select participants hence health providers were sampled from Muhimbili National Hospital, Agha khan, Temeke and Mwananyamala hospitals and including medical students from Muhimbili University of Health and Allied Sciences (MUHAS). The composition of health providers included nurse midwifery, nurse officers, clinical officers, assistant medical officers, medical officers, physicians and $4^{\text {th }}$ and $5^{\text {th }}$ year medical students who had finished internal medicine rotation and $3^{\text {rd }}$ year nursing students. The fish consumers were residents of Ilala, Temeke and Kinondoni Municipals (Bulula).

\subsection{Sample Size Determination}

This was determined based on estimating the prevalence of fish associated allergic reactions among residents in Dar es Salaam by using the following statistical formula: 


$$
N=(Z / W)^{2} \times p(1-p)
$$

where $N=$ required sample size;

$W=$ margin of error (standard value of 0.05 );

$P=$ estimated prevalence (0.5);

$Z=$ confidence interval level at $95 \%$ (standard value of 1.96 ).

Hence, number of participants $(N)=(1.96 / 0.05)^{2} \times 0.5 \times 0.5=384.16$ which approximate to 385 participants [22].

\subsection{Data Collection Methods}

Data were collected using structured questionnaires (Appendix I and Appendix II) as previous reported [9]. These questionnaires were pretested and improved accordingly. Four trained data collectors were involved in data collection; two data collectors visited the health facilities to interview health providers and the other two visited various parts of the city of Dar es salaam to interview other residents the fish consumers. Participants were asked for their consent to participate in the study. About 385 Dar es Salaam residents participated in the study of which 280 were fish consumers and 105 health care providers.

The questions administered sought to measure two contributing factors namely level of awareness and specific knowledge regarding scombroid fish poisoning. Awareness as a contributing factor was judged by the question whether they had experienced any problems after fish consumption or have heard of people experiencing problem after eating fish as well as the description of any unusual signs and symptoms observed. In the healthcare providers, awareness of scombroid fish poisoning was determined by the description of the clinical features observed and their distinguishing features. Based on literature review, a set of ten statements representing the commonest signs and symptoms, duration of symptoms presentation and elapse, causes of scombroid fish poisoning as well as fish icing importance were designed for fish consumers to assess their knowledge [9]. For health providers twenty pre-set statements describing symptoms, signs and causes of HFP, and additional ten statements for management of histamine fish poisoning were used to gather information. Participants were asked to give their response to these pre-set questions by writing "Yes", or "No" to the answer. Each correct response scored one and incorrect response scored zero. Knowledge of scombroid fish poisoning among health care personnel and fish consumers was assessed by score marks. Those who score questions $>70 \%$ were considered to have good knowledge, $40 \%$ - 69\% average knowledge and $<40 \%$ low knowledge [9].

\subsection{Data Analysis Plan}

Questionnaires were checked and edited for any inconsistence or discrepancies. Data collected was coded, entered, cleaned and analysed using the "Statistical Package for Social Sciences” (SPSS) software version 17 (SPSS Inc., Chicago, IL, USA). Results were summarized using descriptive statistics such as frequency distribution, mean, bar charts, and cross tabulation whenever necessary and a 
test for Chi square was done and the significance level was set at $(P \leq 0.05)$.

\subsection{Ethical Consideration}

All participants were interviewed only after getting their written informed consent. They were informed on the objectives of the study, confidentiality of the information they provide and that their participation was voluntary.

\section{Results and Discussion}

A total of 105 health care personnel with different back ground training and 280 fish consumer, male and female of different age groups participated in this study (Table 1).

Table 1. Univariate analysis for association between awareness of scombroid fish poisoning with various variables.

\begin{tabular}{|c|c|c|c|}
\hline \multicolumn{4}{|c|}{ Health care personnel $(n=63)$} \\
\hline Variable & Awareness & Chi square value & $P$ value \\
\hline SEX: Male $(\mathrm{n}=43)$ & $68.3 \%$ & 1.324 & 0.247 \\
\hline Female $(n=20)$ & $31.7 \%$ & & \\
\hline \multicolumn{4}{|l|}{ PROFESSION: } \\
\hline Nursing officer $(n=10)$ & $15.9 \%$ & & \\
\hline Nursing Midwifery $(n=2)$ & $3.2 \%$ & & \\
\hline Clinical officer $(n=7)$ & $11.1 \%$ & & \\
\hline Assistant Medical officer $(n=6)$ & $9.5 \%$ & & \\
\hline Medical officer $(n=10)$ & $15.9 \%$ & & \\
\hline Specialists $(\mathrm{n}=9)$ & $14.3 \%$ & & \\
\hline Medical students $(\mathrm{n}=19)$ & $30.2 \%$ & 17.199 & 0.009 \\
\hline \multicolumn{4}{|l|}{ Fish consumers $(n=37)$} \\
\hline SEX: Male $(\mathrm{n}=20)$ & $54.1 \%$ & & \\
\hline Female $(n=17)$ & $45.9 \%$ & 3.758 & 0.153 \\
\hline \multicolumn{4}{|l|}{ AGE: } \\
\hline $15-25$ years $(n=13)$ & $35.1 \%$ & & \\
\hline $26-40$ years $(n=16)$ & $43.2 \%$ & & \\
\hline $41-65$ years $(n=8)$ & $21.6 \%$ & 6.641 & 0.156 \\
\hline \multicolumn{4}{|l|}{ Frequency of eating fish in a week } \\
\hline $\operatorname{ONCE}(n=6)$ & $16.2 \%$ & & \\
\hline TWICE $(\mathrm{n}=14)$ & $37.8 \%$ & & \\
\hline THRICE $(n=4)$ & $10.8 \%$ & & \\
\hline OFTEN $(\mathrm{n}=13)$ & $35.1 \%$ & 7.999 & 0.238 \\
\hline \multicolumn{4}{|l|}{ Type of preparation of cooked fish } \\
\hline Roasted $(\mathrm{n}=2)$ & $5.4 \%$ & & \\
\hline Fried $(n=9)$ & $24.3 \%$ & & \\
\hline Dried/Smoked $(\mathrm{n}=8)$ & $21.6 \%$ & & \\
\hline Fried and Roasted $(\mathrm{n}=8)$ & $21.6 \%$ & & \\
\hline Any $(n=10)$ & $27.0 \%$ & 22.234 & 0.004 \\
\hline
\end{tabular}


The results showed that awareness of scombroid fish poisoning among fish consumers interviewed was $49.6 \%$ and significantly $(P<0.005)$ associated with the method of preparation but insignificantly associated with sex $(P=0.153)$, age group $(P=0.156)$ and frequency of eating fish $(P=0.238)$ (Table 1$)$. Among fish consumers with awareness, $73.4 \%$ stopped eating the same type of fish on fearing to re-encounter similar problems as advised by their clinicians. However, the awareness among health care providers was $60 \%$ and significantly associated with the profession status $(P<0.005)$ and insignificantly associated with sex $(P>0.05)$.

All respondents with awareness of scombroid fish poisoning responded to the pre-set questions assessing specific knowledge. Health care providers on a 20-point question-scale pertaining to knowledge of signs, symptoms and management recorded a mean score of 9.91 (standard Error of Mean (SEM) 0.285), well below average score. The fish consumers pertaining to signs and symptoms recorded a mean score of 2.24 (SEM 0.088) on a 10-point question-scale.

The study showed that about $32(50.8 \%)$ of the health care providers had low knowledge, 27 (42.9\%) had average knowledge and 4 (6.3\%) had good knowledge of scombroid fish poisoning (Figure 1). Among those with low knowledge, medical students were $40.6 \%$ and nursing officers $31.25 \%$. Physicians (specialists) were the only group with good knowledge (100\%) among all respondents. (Figure 2). Fish consumer, 136 (97.8\%) had low knowledge and $3(2.2 \%)$ had average knowledge. For those with low knowledge category, male was 88 (64.7\%) and female 48 (35.3\%).

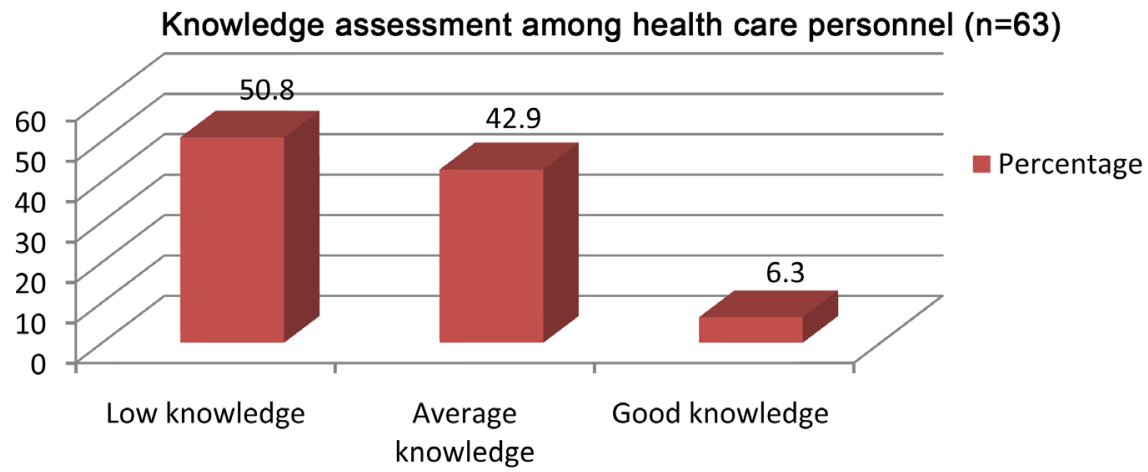

Figure 1. Knowledge level of scombroid fish poisoning among health personnel.



Figure 2. Cross tabulation of knowledge level vs. profession. 
The study also showed that 74 (53.2\%) of the fish consumers mentioned the cause of fish associated allergic reaction was due to the body naturally being allergic to the fish, $33(23.7 \%)$ said could be to eating spoiled fish that have poison (high histamine) and 32 (23\%) responded don't know the cause. Fish consumers when asked for the importance of fish icing, $86.3 \%$ indicated it's of benefit for prevention of fish spoilage and $13.7 \%$ said had no benefit rather makes the fish tasteless. Elsewhere, studies have demonstrated the importance of fish icing where the level of histamine in mackerel stored at $0^{\circ} \mathrm{C}$ for 18 days was low as compared to high histamine level in mackerel stored at $10^{\circ} \mathrm{C}$ for only 5 days [8]. Generally, at a temperature of $4.4^{\circ} \mathrm{C}$, the storage life of fishery products is shorter [6] [7] [8]. For example, if scombroid fish is frozen immediately after catch at $0^{\circ} \mathrm{C}$, its storage life will be 14 days, but at $4.4^{\circ} \mathrm{C}$, it is only 7 days [8]. Since most bacteria cannot grow at temperatures below $4^{\circ} \mathrm{C}$, freezing of fishery products during transportation is of great importance. When asked what advice do they give the patients once have histamine fish poisoning, 38 (60.3\%) of the health care providers advised the patient not to eat the same fish again, 14 (22.2\%) advised not to eat any fish again and $11(17.5 \%)$ did advise nothing. A study by Stomel et al. however, mentioned histamine fish poisoning is a foodborne intoxication related to elevated histamine levels, and therefore the patient can safely eat the same type of fish again with impunity [23].

The current study showed that most respondents recorded skin rashes (59\%) as being the commonest symptoms associated with scombroid fish poisoning followed by diarrhoea (21.6\%) and skin itching (19.4\%). The same results were observed by Muller et al., 1992 who reported diarrhoea as a prominent clinical sign in $77 \%$ of patients (second in frequency only to skin rash, which occurred in $82 \%$ ) in ten incidents of HFP involving 22 patients in South Africa [24]. Other studies also mentioned the same symptoms and signs being associated with HFP [4] [8] [10] [11] [12]. Although there is no information on the incidence of scombroid fish poisoning in Africa, and mortality is usually rare, health care personnel should not neglect it especially to individuals with pre-existing cardiac and respiratory condition such as coronary artery disease and bronchial asthma. In these patients, serious complications such as cardiac and respiratory collapse can occur in case they eat fish with excessive amount of histamine [25] [26] [27].

This study also indicated that both salty and fresh water fishes, scombroid and non scromboid can be implicated in scombroid fish poisoning (Figure 3 and Figure 4). Mackerel was frequently mentioned among scromboid fish by fish consumers, followed by tuna and king fish, and for non scombroid fish, Octopus followed by Claria and Nile Perch was frequently listed. Other studies have also implicated mackerel to have been associated with HFP [6] [8].

\section{Conclusion and Recommendation}

This study demonstrated low awareness and knowledge of histamine fish poisoning as major contributing factors of scombroid fish poisoning among Dar es 
Fish types listed by fish consumers associated with HFP

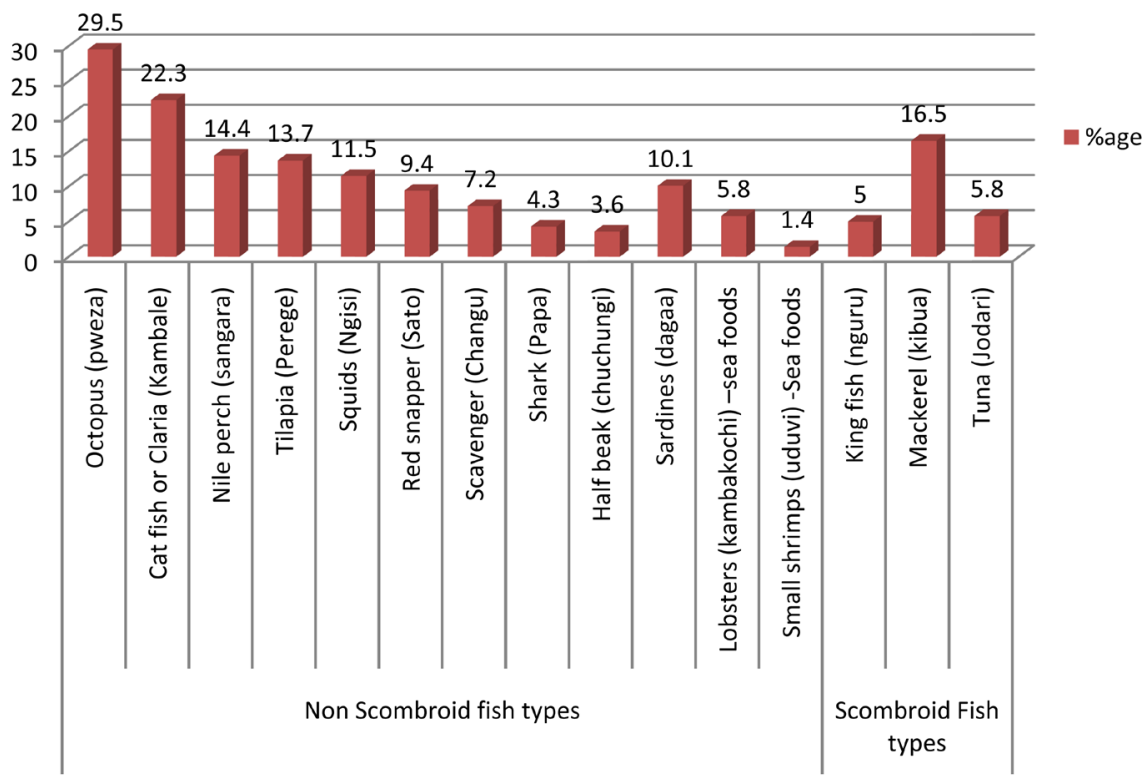

Figure 3. Fish types associated with allergic reaction (fish consumers).

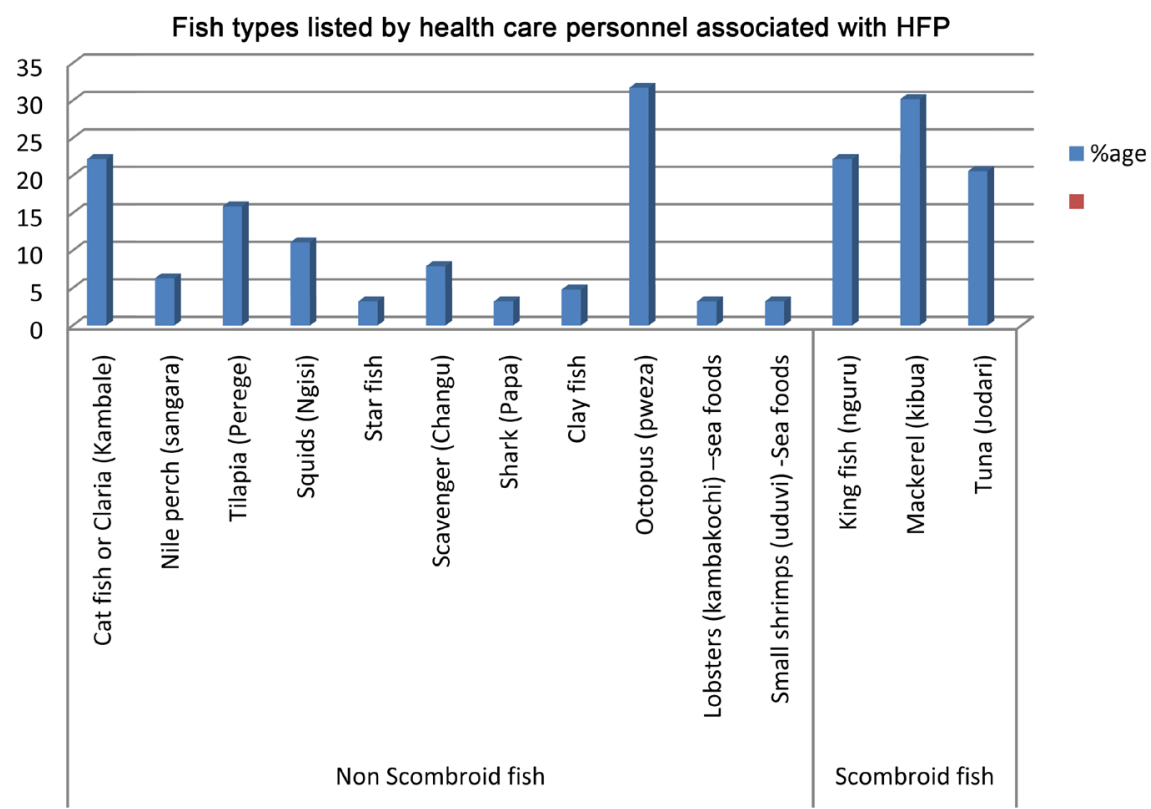

Figure 4. Fish types listed by health care personnel associated with HFP.

Salaam city residents. Health care providers with low knowledge could be a source to the community being wrongly advised not to eat same fish for fear of redeveloping same scombroid fish poisoning reactions. Knowledge on histamine fish poisoning and the benefit from fish icing should be disseminated to fish vendors and consumers in the city. This can reduce fish spoilage due to increase in histamine content in fish during storage. However, one of the limitations of the current study was unavailability of an equipped laboratory that could be involved in investigations to confirm the histamine content in suspected fishes. 
Other studies should be carried out to check the histamine contents in fish that have been listed by fish consumers and health care personnel. Nonetheless aggressive health promotion intervention should be designed to increase awareness of scombroid fish poisoning and correct diagnostic measures to the general public and health care providers.

\section{Acknowledgements}

The authors wish to acknowledge all respondents in Ilala, Temeke and Kinondoni Municipal who participated in this study. Also they acknowledge the Kigamboni district ferry fish market officials for their support they provided when interviewing fish consumers. Further, authors express their thanks to Ministry of Health and Social Welfare for sponsoring the current study.

\section{Conflict of Interest}

The authors declare no conflict of interest.

\section{References}

[1] BC Centre for Disease Control (2008) Fish Safety Notes, Scombroid Fish Poisoning; Histamine Poisoning. http://www.bccdc.org/

[2] Etkind, P., Wilson, M.E., Gallagher, K., et al. (1987) Bluefish-Associated Scombroid Poisoning. An Example of the Expanding Spectrum of Food Poisoning from Seafood. JAMA, 258, 3409-3410. https://doi.org/10.1001/jama.1987.03400230069034

[3] FDA (1996) Decomposition and Histamine in Raw Frozen Tuna, and Mahi-Mahi, Canned Tuna; and Related Species. Compliance Policy Guides, 240, 525-540.

[4] Lehane, L. and Olley, J. (2000) Histamine Fish Poisoning Revisited. International Journal of Food Microbiology, 58, 1-37. https://doi.org/10.1016/S0168-1605(00)00296-8

[5] Sapin-Jaloustre, H. and Sapin-Jaloustre, J. (1957) A Little-Known Food Poisoning: Histamine Poisoning from Tuna. Concours Medicine Paris, 79, 2705-2708.

[6] Chamberlain, T. (2001) Histamine Levels in Longlined Tuna in Fiji: A Comparison of Samples from Two Different Body Sites and Effect of Storage at Different Temperatures. The South Pacific Journal of Natural Science, 19, 30-34.

[7] Wu, M.L., Yang, G.Y., Yang, C.C., Ger, J. and Deng, J.F. (1997) Scombroid Fish Poisoning: An Overlooked Marine Food Poisoning. Veterinary and Human Toxicology, 39, 236-241.

[8] Mitchell, J. (1993) Scombrotoxic Fish Poisoning. Report for the Ministry of Health, Wellington.

[9] Ngwegwe, B. (2012) Masters of Pharmacy (Clinical Pharmacy). Dissertation, Muhimbili University of Health and Allied Sciences.

http://ihi.eprints.org/1613/1/Ngwegwe_Bulula\%2C_B.Pharm.pdf

[10] Clifford, M.N., Walker, R. and Wright, J. (1989) Studies with Volunteers on the Role of Histamine in Suspected Scombrotoxicosis. Journal of the Science of Food and Agriculture, 47, 365-375. https://doi.org/10.1002/jsfa.2740470311

[11] Hwang, D.F., Chang, S.H., Shýau, C.Y. and Cheng, C.C. (1995) Biogenic Amines in the Flesh of Sailfish (Istiophorus platypterus) Responsible for Scombroid Poisoning. Journal of Food Science, 60, 926-928. 
https://doi.org/10.1111/j.1365-2621.1995.tb06263.x

[12] Kaneko, J.J. (2000) Development of a HACCP-Based Strategy for the Control of Histamine for the Fresh Tuna Industry. Final Report NOAA Award NA86FD0067, Pac Mar, Inc., Honolulu.

[13] Gilbert, R.J., Hobbs, G., Murray, C.K., et al. (1980) Scombrotoxic Fish Poisoning: Features of the First 50 Incidents to Be Reported in Britain. BMJ, 2, 71-72.

[14] Maire, R., Dreiding, K. and Wyss, P.A. (1992) Incidence and Clinical Aspects of Scombroid Fish Poisoning. Schweizerische Medizinische Wochenschrift, 122, 1933-1935.

[15] Bartholomev, B.A., Berry, P.R., Rodhouse, J.C. and Gilhouse, R.J. (1987) Scombrotoxic Fish Poisoning in Britain: Features of over 250 Suspected Incidents from 1976 to 1986. Epidemiology \& Infection, 99, 775-782. https://doi.org/10.1017/S0950268800066632

[16] Becker, K., Southwick, K., Reardon, J., Berg, R. and MacCormack, J.N. (2001) Histamine Poisoning Associated with Eating Tuna Burgers. JAMA, 285, 2977-2978. https://doi.org/10.1001/jama.285.10.1327

[17] Attaran, R.R. and Probst, F. (2002) Histamine Fish Poisoning; A Common but Frequently Misdiagnosed Condition. Emergency Medicine Journal, 19, 474-475. https://doi.org/10.1136/emj.19.5.474

[18] Miki, M., Ishikawa, T. and Okayama, H. (2005) An Outbreak of Histamine Poisoning after Ingestion of the Ground Saury Paste, to Eighteen Patients Taking Isoniazid in Tuberculous Ward. Internal Medicine, 44, 1133-1136. https://doi.org/10.2169/internalmedicine.44.1133

[19] Auckland Allergy Clinic, 185 Jervois Road Herne Bay, Auckland Bay, New Zeland +6493766185; Scombroid (Histamine) Fish Poisoning and Other Seafoods-Related Illnesses Masquerading as Allergies.

[20] Muhimbili National Hospital (2012). http://www.mnh.go.tz

[21] National Bureau Statistics of Tanzania (2011). http://www.nbs.go.tz

[22] Ravindra, A., et al. (2012) Sample Size Estimation in Prevalence Studies. Indian Journal of Pediatrics, 79, 1482-1488. https://doi.org/10.1007/s12098-012-0763-3

[23] Stommel, E.W. (2017) Scombroid Fish Poisoning Infectious Diseases. Human Press Inc., Totowa. http://eknygos.lsmuni.lt/springer/655/375-381.pdf

[24] Muller, G.J., et al. (1992) Scombroid Poisoning. Case Series of 10 Incidents Involving 22 Patients. South African Medical Journal, 81, 427-430.

[25] Ascione, A., et al. (1997) Two Cases of "Scombroid Syndrome" with Severe Cardiovascular Compromise. Cardiologia, 42, 1285-1288.

[26] Shalaby, A.R. (1996) Significance of Biogenic Amines to Food Safety and Human Health. Food Research International, 29, 675-690.

[27] Russsel, F.E. and Maretic, Z. (1986) Scombroid Poisoning: Mini-Review with Case Histories. Toxicon, 24, 967-973. 


\section{Appendix I: Questionnaire for Health Care Personnel}

Muhimbili university of health and allied sciences School of pharmacy

Topic: Assessment of knowledge of Histamine Fish

Poisoning among Health care personnel in Dar es Salam region

Dear Participant, thank you for taking your time and participate in filling this questionnaire. This questionnaire intends to seek information on knowledge of histamine fish poisoning among health care personnel in Dar es Salaam. The researcher is a post graduate student at MUHAS; and the information you give will be used for academic purposes, therefore will be confidential and there is no need to write your name in this form.

A: Participant information - Health care personnel (TICK where appropriate)

Sex:
(a) $\mathrm{M}$
(b) $\mathrm{F}$

\section{Health facility:}
(a) Public
(b) Private

\section{Profession:}
(a) Nurse Midwifery
(b) Nurse Officer
(c) Clinical Officer
(d) Assistant Medical Officer.
(e) Medical Officer
(f) Specialist
(g) Medical student (nursing, MD)
B: General knowledge Questions (Tick the correct response)
1) In your carrier have you attended any patient who complained suffering after fish consumption? OR have you heard of people suffering after eating fish?
(a) YES
(b) $\mathrm{NO}$
2) If Yes (a), List any type of fish that you know, are mostly associated with the problem.
(a) $\times \times x$
(b) $\times \times \times$
(c) $x \times \times$
3) If YES No.1 did you take or request any allergy test?
(a) YES
(b) $\mathrm{NO}$
Allergy test:
(a) Positive
(b) Negative

4) If the allergy test was POSITIVE or NEGATIVE what did you advice the patient? 
Advice to the patient:
(a) Don't eat the same fish again
(b) Don't eat any fish again
(c) NONE
C: Specific knowledge questions (Tick where appropriate)
1) There is no difference between histamine fish poisoning and fish associated allergic reaction
(a) YES
(b) $\mathrm{NO}$
2) Patient with histamine fish poisoning usually present with negative allergy test
(a) YES
(b) $\mathrm{NO}$
3) Scombroid fish are mostly associated with histamine fish poisoning
(a) YES
(b) $\mathrm{NO}$

The following are symptoms and signs most patient present with histamine fish poisoning and its onset and elapse:

1) Nausea and Vomiting
(a) YES
(b) $\mathrm{NO}$
2) Diarrhea
(a) YES
(b) $\mathrm{NO}$
3) Skin itching
(a) YES
(b) $\mathrm{NO}$
4) Rashes and pruritis
(a) YES
(b) $\mathrm{NO}$
5) Body swelling
(a) YES
(b) $\mathrm{NO}$
6) Abdominal cramp or stomach ache
(a) YES
(b) $\mathrm{NO}$
(a) YES
(b) $\mathrm{NO}$

7) Dyspnoea

Management of histamine fish poisoning may involve the following:

1) Antihistamine and corticosteroids
(a) YES
(b) $\mathrm{NO}$ 
2) Antihistamine alone
(a) YES
(b) $\mathrm{NO}$
3) Antihypertensive especially adrenaline
(a) YES
(b) $\mathrm{NO}$
4) NSAIDs

(a) YES

(b) $\mathrm{NO}$

5) Antibiotics like ciprofloxacin
(a) YES
(b) $\mathrm{NO}$
6) Methotrexate
(a) YES
(b) $\mathrm{NO}$
7) HFP present within 10 min to 24 hours
(a) YES
(b) $\mathrm{NO}$
8) Symptoms may subside 4-6hrs rarely $48 \mathrm{hrs}$
(a) YES
(b) $\mathrm{NO}$

9) Do you think there is a difference between fish-associated allergy and histamine fish poisoning?
(a) YES
(b) $\mathrm{NO}$
10) If YES No.7, give reason(s)
(a) YES
(b) $\mathrm{NO}$

THE END

\section{Appendix II: Questionnaire for Fish Consumers}

Muhimbili university of health and allied sciences school of pharmacy

Topic: Assessment of knowledge of Histamine Fish

Poisoning among fish consumers in Dar es Salaam

Dear participant, thank you for taking your time and participate in filling this questionnaire. This questionnaire intends to seek information on knowledge of histamine fish poisoning among fish consumers in Dar es Salaam. The researcher is a post graduate student at MUHAS; and the information you give will be used for academic purposes, therefore will be confidential and there is no need to write your name in this form. 
A: Participants Information-Fish consumers (TICK where appropriate) SEX:
(a) $\mathrm{M}$
(b) $\mathrm{F}$

Age: $x \times x$

B: General knowledge Questions (TICK where appropriate)

1) In your life time, have you eaten fish?
(a) YES
(b) NO
2) How many types of fish do you know?
(a) Above 10
(b) Below 10
(c) I don't know
3) What cooked fish preparation do you prefer?
(a) Toasted
(b) Fried
(c) Smoked
(d) Fried and Toasted
(e) Any
4) How many times do you eat fish in a week?
(a) Once
(b) Twice
(c) Thrice
(d) Often

5a) Had you experienced any problem after eating fish? OR have you heard of any person experiencing problem after fish consumption?
(a) YES
(b) $\mathrm{NO}$
5b) If YES, List the type of fish that was associated with the problem.
(a) $x \times x$
(b) $x \times x$
(c) $x \times x$
(d) $x \times x$
(e) $x \times x$
6) Fish associated with the problem(s) was in what preparation?
(a) Toasted
(b) Fried
(c) Smoked
(d) Smoked and toasted
(e) Any form
7) What did you do after symptoms presentation?
(a) I went to the hospital
(b) I self medicate
(c) I did nothing 
8a) After symptoms resolve, are you still eating the same fish?
(a) YES
(b) NO
8b) Why?

(a) I'm afraid not to encounter another problem

(b) Nothing happens even when I eat

(c) I have been advised by the doctor not to eat again

9) From your understanding, what is the cause of the problem you encountered after fish consumption?
(a) The fish had "poison"
(b) The fish was spoiled
(c) I have allergy with that fish
(d) I don't know
C: Specific Knowledge Questions (Tick where appropriate)

The following are symptoms and signs most patient present with histamine fish poisoning and its onset and elapse:

1) Nausea and Vomiting
(a) YES
(b) NO
2) Diarrhea
(a) YES
(b) NO
3) Skin itching
(a) YES
(b) NO
4) Rashes and pruritis
(a) YES
(b) NO
5) Body swelling
(a) YES
(b) $\mathrm{NO}$
6) Abdominal cramp or stomach ache
(a) YES
(b) NO
7) Dyspnoea
(a) YES
(b) NO
8) Dizziness or Giddiness
(a) YES
(b) NO

9) Symptoms may present within $10 \mathrm{~min}$ to $24 \mathrm{hrs}$
(a) YES
(b) NO 
10) Symptoms may subside $4-6 \mathrm{hrs}$ rarely $48 \mathrm{hrs}$

(a) YES

(b) $\mathrm{NO}$

Submit or recommend next manuscript to OALib Journal and we will provide best service for you:

- Publication frequency: Monthly

- 9 subject areas of science, technology and medicine

- Fair and rigorous peer-review system

- Fast publication process

- Article promotion in various social networking sites (LinkedIn, Facebook, Twitter, etc.)

- Maximum dissemination of your research work

Submit Your Paper Online: Click Here to Submit

Or Contact service@oalib.com 